\title{
Wage Premia and Skill Upgrading in Italy: Why didn't the Hound Bark?*
}

\author{
Paolo Manasse Luca Stanca $^{\ddagger}$ Alessandro Turrini ${ }^{\S}$
}

October 2001

\begin{abstract}
This paper presents firm level evidence on the change of nonmanual wage premia and employment shares in Italian manufacturing during the nineties. We find that the relative stability of aggregate wage premia and employment shares hides offsetting disaggregate forces. First, while technical progress raises the relative demand for skilled labor within firms, demand changes associated with exports reduce the relative demand for skills. Second, within the class of nonmanual workers, wage premia and employment shares of executives rise substantially, whereas those of clerks fall in a similar proportion. We also find that the export status of firms plays a key role in explaining labour market dynamics, as exporters account for most of both demand-related and technology-related shifts. Overall, our results for Italy question the general validity of the conventional view that emphasizes the role of labor market institutions, as opposed to trade and technology, in determining wage and employment dynamics in continental Europe.
\end{abstract}

${ }^{*}$ We thank Federmeccanica for kindly providing the data for this study. We are indebted to Ivan Briozzo for excellent research assistance. Andrea Gavosto, Robin Naylor, Giammarco Ottaviano, Beniamino Quintieri, as well as partecipants to seminars at IGIERBocconi, CRENOS (Cagliari), provided useful comments.

${ }^{\dagger}$ Corresponding author. Department of Economics, University of Bologna, Strada Maggiore 45, 40100, Bologna, Italy. Email: manasse@spbo.unibo.it

$\ddagger$ University of Milan and London School of Economics. E-mail: stanca@lse.ac.uk

$\S$ Dept. of Economics, University of Bergamo, Email: alessandro.turrini@uni-bocconi.it 


\section{Introduction}

In Conan Doyle's "The Hound of the Baskervilles" (1901-2), Sherlock Holmes suggests that sometimes the key to solving a mystery is to understand why something that should have happened, actually did not happen. In that case, the hound should have barked at the intruder, but it didn't because it was familiar with the killer. In this paper the "mystery" is the following: why did the non-manual relative wage and employment shares remain virtually unchanged in Italy in the past decade, despite rapid technical change and trade integration? Unless we are willing to accept that Italy was unaffected by the IT revolution or by globalization, or that labour market "rigidity" accounted for the stability of both relative wages and employment shares, there is a puzzle to be solved. Our solution to the puzzle has two parts.

First, technology and demand shocks associated with demand and exports have indeed affected wage premia and factor proportions, but they have acted in opposite directions, thus largely offsetting each other. On the one hand, skill-biased technical progress played, qualitatively and quantitatively, its expected role, namely it raised the relative demand for skilled labor within firms. On the other hand, quite surprisingly, demand and trade related changes reduced the relative demand for skills: employment shifted towards firms producing unskilled-intensive goods, offsetting the effect of technology upon factor proportions and wage shares. ${ }^{1}$

The second part of the explanation is that the stability over time of the aggregate non-manual relative wage and employment share hides a fallacy of composition. Whereas relative wages and employment shares are stable for the class of non-manual workers as a whole, the same does not apply to its individual components. In order to understand what happens within the class of non manual workers, we disaggregate non-manual workers into clerks (impiegati) and executives (quadri). We find that the modest overall change in the non-manual relative wage and employment share is an artifact of aggregation, as it results from two large offsetting forces: a rise in the wage premia and employment shares of executives, and a corresponding fall in the wage premia and employment shares of clerks. These findings suggest that trade and technology have had noticeable effects on wage inequality and skill upgrading in Italy in the past decade. However, these effects had opposite

\footnotetext{
${ }^{1}$ As explained in section 4 , one possible interpretation of the effect of trade rests on the peculiar specialization pattern of Italian metal-mechanical firms.
} 
signs and largely offset each other. Moreover, the rise in wage inequality and skill upgrading mainly occurred within the category of non-manual workers (that is, between executives and clerks) rather than between manual and non-manual workers.

In addition to the solution to the puzzle, the analysis reported in this paper suggests two other important conclusions. First, there is evidence that the export status of firms matters substantially in explaining labor market dynamics in the past decade. In particular, exporters account for most of both demand-related and technology-related dynamics. While labor has been shifting towards low-skill intensive exporting firms, these firms have been those more actively engaged in skill-upgrading. Second, quite surprisingly, institutional factors such as union power and centralized bargaining do not seem to affect the dynamics of relative factor prices and shares. Overall, the results of our analysis cast several doubts on the validity of the conventional view that emphasizes the role of labor market institutions, as opposed to trade and technology, in determining wage and employment dynamics in continental Europe.

The paper is structured as follows. Section 2 places the analysis in the context of the literature. Section 3 provides a brief description of the data set. In section 4 we present the results of the decomposition of the change in the non-manual share of the wage bill into its (within and between) employment share and relative wage components. Section 5 takes a closer look at the manual-non manual classification, by extending the analysis to the further disaggregation of non-manual workers into clerks and executives. In section 6 we use regression analysis to verify if the interpretation of the decompositions in terms of technology and trade is supported by the data. The concluding section summarizes the results and discusses the main implications.

\section{Trade, technology, and labor market ad- justment}

The widening of skill premia and the rise of the employment share of skilled workers in the past two decades are well documented for the US (Katz and Murphy (1992), Bound and Johnson (1992), Lawrence and Slaughter (1993), Berman, Bound, and Griliches (1994)), and other OECD countries (Haskel and Slaughter (2001a), Machin, Berman, and Bound (1998), Machin and 
Van Reenen (1998), Card, Kramarz, and Lemieux (1998)). Because skillpremia and employment shares have both risen, most studies have focused on factors underlying shifts in the relative demand for skilled workers, trade and technology being the main suspects (for recent surveys on this debate see e.g. Haskel (2000), Slaughter (1998), (1999)).

The argument for technology runs as follows: the computer revolution, by fostering the relative productivity of more educated workers, has led to higher relative demand for skilled workers, resulting in higher wage premia and employment shares for non-manual workers. This argument, based on the skill-bias of technological change, is consistent with the observed ITinduced growth in productivity observed in the US. ${ }^{2}$

International trade can produce similar effects on the labor market through inter-sectorial demand shifts (see e.g. Richardson (1995), Wood (1995) for recent surveys). Increased trade with (and import competition from) developing countries has lowered product demand in the North in sectors producing unskilled labor-intensive goods. As resources have shifted to sectors intensive of skilled labor, the relative demand for manual workers has fallen. This argument is consistent with the trends towards "globalization", documented, for example, by the acceleration of the growth of trade in goods and services in the recent past.

The broad consensus emerging from the empirical literature, generally based on industry data, is that, while international trade did account for some of the rise in wage differentials, most of the action was due to skill biased technical progress (see e.g. Berman et al. (1994)). ${ }^{3}$ This view, however, has been challenged recently by a new stream of empirical research based on panels of firms/plants. ${ }^{4}$ In particular, Bernard and Jensen (1997) find that the shifts in relative employment have occurred mainly between plants belonging to the same sector (see also Bernard and Jensen (1995)), and these changes are strongly associated with shifts in product demand. Trade seems

\footnotetext{
${ }^{2}$ In a multisector perspective with exogenous good prices, however, it is the sector rather than the factor bias of technical progress that matters (see Leamer (1998), but also Krugman (1995), Haskel (2000), Haskel and Slaughter (2001b)).

${ }^{3}$ The same conclusion has been reached using both price (e.g. Leamer (1996), Feenstra and Hanson (1996)) and volume (e.g., Borkas, Freeman and Katz (1997)) data to capture the effect of trade on the labor market.

${ }^{4}$ Most of plant and firm level analyses are aimed at assessing the links between exporting activity and productivity (see, e.g., Bernard and Jensen (1999) and Bernard et al. (2000)) or the existence of learning effects associated with the exports status of firms (see, e.g., Clarides, Lauch and Tybout (1998)).
} 
to have played a major role, as exporters account for most of the changes in relative wages and factor shares. ${ }^{5}$ The conclusion is that significant dynamics occur at the level of individual establishments, so that the earlier studies which use industry data may have substantially underestimated the role of demand.

In continental Europe, labor market developments in the past two decades have been markedly different from those observed in the US: relative earnings have remained relatively flat, while most of the adjustment seems to have taken place on the quantity side, with relative unemployment rates for skilled workers falling in most countries (see OECD (1997), Freeman and Katz (1996)). The lack of adjustment in relative wages in the face of supposedly pervasive technical progress has been generally attributed to the rigidity of European labor markets. The conventional wisdom for Europe is that, due to labor market institutions (minimum wages, hiring and firing costs, centralized bargaining and union power, etc.), unemployment rates have taken the brunt of the falling demand for manual workers. In other words, according to this view, European labor markets are "rigid", so that relative wages do not adjust, nor firms are able to hire or fire workers.

The evidence on the role of technology and trade for labor market dynamics in Italy is relatively limited. Erickson and Ichino (1995) exploit discuss the role of labor market institutions in causing compressed wage differentials. Quintieri and Rosati (1995) and Quintieri and Ferragina (1998) use firm-level data to discuss the relationship between export activity, productivity and performance, while Dell'Aringa and Lucifora (1994) look at a cross section of metal-mechanical firms to discuss the role of trade unions in affecting earnings differentials. ${ }^{6}$

Against this background, we present some new evidence on the role of trade, technology and labor market institutions for skill upgrading and wage inequality, based on data for Italian manufacturing firms during the midnineties. The firms in our data set belong to the metal-mechanical sector, which alone accounts for more than 40 per cent of manufacturing value added and 50 per cent of manufacturing exports, and can be reasonably taken as representative of the developments in the manufacturing sector in Italy.

\footnotetext{
${ }^{5}$ For a theoretical explanation of this evidence see Manasse and Turrini (2001).

${ }^{6}$ See also Dell' Aringa and Lucifora (2000) for an overview of the role of institution sin explaining a compressed wage structure in Italy.
} 


\section{Data description}

The analysis is based on firm-level survey data set collected by Federmeccanica, the entrepreneurs association of the Italian metal-mechanical sector. The survey covers firms operating in metallurgy, mechanics, vehicles constructions and reparations, plant installation and technical projects. Roughly 60000 firms belong to the metal-mechanical sector, employing about one and a half million workers in year 2000. In the same year these firms accounted for 40 per cent of value added and 50 per cent of exports of the overall Italian manufacturing sector.

The panel covers 2837 firms, observed between 1995 and 1997. ${ }^{7}$ About eighty per cent of the firms in the sample are located in Northern Italy, while 17 and 2 per cent are located, respectively, in Central and Southern Italy. The survey reports information on employment and salaries for 16 classes of workers falling into two main categories: manual workers (trainees and production workers), and non-manual (clerks and executives). The data set also contains information on union activity, bargaining, turnover, revenues, outsourcing, exports and investments (see also Dell'Aringa and Lucifora (1994) for a description of the data set).

Wage premia and employment shares have been relatively flat in Italian manufacturing in the recent past (see ISTAT (2000), OECD (1997), Erickson and Ichino (1995)). The metal-mechanical sector is no exception: between 1990 and 1998 the employment shares of manual and non-manual workers were stable around 63.6 and 34.4 per cent, respectively (see Federmeccanica (2000)). These features of manufacturing and of the metal-mechanical sector are mirrored in our sample. Table 1 presents summary statistics for the aggregate share of non-manual workers in the wage bill (WBnWB) and its components: the employment share $(\mathrm{EnE})$ and the relative wage $(\mathrm{WnW})$. The share of non manual workers in the wage bill has risen by a modest 0.5 per cent between 1995 and 1997. As for its components, the wage premium has risen by just $0.7 \%$, while the non-manual employment share has gone up by 1.3 per cent.

Substantial variation can be observed in sub-samples based on firms' char-

\footnotetext{
${ }^{7}$ The available evidence suggests that these were the years when most of innovation and restructuring activity has occurred the US (Oliner and Sichel (2000), Jorgenson and Stiroh (2000), Black and Lynch (2000)),, while Italy and Europe lagged a few years (Daveri (2001)) Italian investment and exports, however, were buoyant between 1995 and 1997 (exports yearly growth was $5.8 \%$ ).
} 
acteristics such as size, geographic location, sector, export status, and the role of unions. Table 1 shows that larger firms tend to have a larger nonmanual wage-bill share, and a larger wage premium. ${ }^{8}$ The few firms located in the South are typically larger and more intensive of manual workers than those in the rest of Italy. Average wages (W) are slightly lower in the South, while relative wages are similar across areas. ${ }^{9}$ There is also much variation among individual sub-sectors. The most skill-intensive firms are in the Precision and Electronic Components. They employ one non-manual worker every two employees. The least skill-intensive firms are in the Transport and Metallurgy sub-sector, with one non-manual worker every four.

Interestingly, exporters tend to pay higher wage premia to non-manual employees. One may suspect that this is just a reflection of the larger size of exporters vis à vis non exporters: the average exporter employs 208 workers, against a figure of 53.3 for non-exporters. Yet size does not explain all, since exporting firms consistently pay higher premia within each dimensional class (see Table 2). ${ }^{10}$ Small and medium exporters pay a higher wage premium and are relatively more skill-intensive. Large exporters, conversely, are relatively more intensive of non-manual workers than non-exporters.

As expected, non-manual shares of employment and of the wage bill tend to be lower in firms where unions are present and strikes occur. This confirms the view that unions and collective bargaining tend to be biased in favour of manual-workers. Again, this may simply reflect a size effect: strikes typically occur in larger firms (average employment is 345 in firms where strikes have occurred at least once, and 68.9 in firms with no strikes), and that is precisely where unions are stronger (average employment is 214.1 in firms with unionized workers against 18.8 in firms where unions are absent). Yet again, as shown in Table 2, this explanation does not fully account for the evidence: the negative association between workers' bargaining power and non-manual shares holds consistently within each size class. The data also suggest that unions do not affect the non-manual wage bill by compressing

\footnotetext{
${ }^{8}$ By definition, a Small firm employs less than 25 workers, a Medium firm between 25 and 100, and a Large more than 100. An Exporter is defined as a firm that ships abroad a fraction of at least one per cent of total sales.

${ }^{9}$ This comparison must be made with caution, since different (average) manual and non-manual wages may reflect a different composition within each category (for example, managers and clerks within non-manual workers).

${ }^{10} \mathrm{It}$ should be noted, however, that exporters are larger than non exporters within each size class.
} 
wage differentials, but rather by raising blue-collar employment. In fact, with the exception of Large firms, the presence of strikes and unions is associated with higher, rather than lower, wage premia.

\section{Firm-level decompositions}

In this section we show that technology and trade effects on labor market dynamics have indeed occurred, although they have largely offset each other. First we decompose the overall change in the non-manual share of the wage bill into the respective contributions of the employment share and the wage premium. Then we split each of these two components further, into their respective between and within components: the former reflects movements between different firms, and the latter changes within the individual firm.

It should be observed that the existing literature generally focuses on the between-within decompositions only for the non-manual share of employment and for the wage bill (see e.g. Berman et al., (1994), Bernard and Jensen (1997), Machin and Van Reenen (1998)). The standard approach, unlike ours, provides only indirect information on movements in relative wages. Furthemore, it is unable to identify the respective contributions of employment and wages to the change in the non-manual wage bill share. We find our approach more intuitive and informative ${ }^{11}$

Let there be $i=1, \ldots, I$ firms, and define $E^{i}=$ employment at firm $i$, $E_{n}^{i}=$ non-manual employment at firm $i, E=\sum_{i} E^{i}=$ overall employment,

$E_{n}=\sum_{i} E_{n}^{i}=$ overall non-manual employment, $W^{i}=\frac{\sum W^{i} E^{i}}{\sum E^{i}}=$ average wage at firm $i, W_{n}^{i}=\frac{\sum W_{n}^{i} E_{n}^{i}}{\sum E_{n}^{i}}=$ average non-manual wage at firm $i, W=$ $\frac{\sum W^{i} E^{i}}{\sum E^{i}}$ economy-wide average wage rate, $W_{n}=\frac{\sum W_{n}^{i} E_{n}^{i}}{\sum E_{n}^{i}}=$ economy-wide average non-manual wage rate. The change in the non-manual share of the total wage bill $\left(W_{n} E_{n} / W E\right)$ can be decomposed as follows:

$$
\Delta\left(\frac{W_{n} E_{n}}{W E}\right)=\Delta\left(\frac{W_{n}}{W}\right) \overline{\left(\frac{E_{n}}{E}\right)}+\Delta\left(\frac{E_{n}}{E}\right) \overline{\left(\frac{W_{n}}{W}\right)}
$$

\footnotetext{
${ }^{11}$ In order to allow a comparison with the existing literature, we report results for our approach (see the "weighted" figures in Tables 3-6) as well as for the traditional one ( see the "unweighted" in Tables 7-10). The Appendix spells out the details of both decompositions.
} 
where $\Delta$ denotes time differences, and the upper bar denotes an average over time. The first term on the right represents the aggregate change in the wage premium, weighted by the average employment share. The second term represents the aggregate change in the non-manual employment share, weighted by the average relative wage rate.

Note that an observed rise in the employment share of non-manual workers may be due to two separate factors: either firms have, on average, become more skill-intensive (within effect) or employment has shifted towards firms producing skill-intensive goods (between effect). Similarly, a higher nonmanual relative wage may be due either to the fact that individual firms have, on average, paid higher skill premia (within effect), or to the fact that average wages have grown more rapidly in firms paying relatively higher skill differentials (between effect). In order to interpret the observed movements in the overall relative wage and employment shares, we therefore decompose the two terms on the right hand side of equation (1) into their between and within components. The (weighted) change in the non-manual employment share can be written as follows:

$$
\Delta\left(\frac{E_{n}}{E}\right)\left(\overline{\frac{W_{n}}{W}}\right)=\sum_{i}\left[\begin{array}{c}
\Delta P_{E w i t}^{i} \overline{S^{i}}+\underset{E b e t}{\Delta S_{n}^{i}} \overline{P_{n}^{i}}
\end{array}\right] \overline{\left(\frac{W_{n}^{i}}{W}\right)}
$$

where $P_{n}^{i}=\frac{E_{n}^{i}}{E^{i}}$ is the proportion of skilled employment at firm $i$, and $S^{i}=\frac{E^{i}}{E}$ is the employment share of firm $i$. The first term on the right hand side is the change in the non-manual employment share that is attributable to the change in the firms' factor proportions, $P_{n}^{i}$, keeping constant their relative size. This reflects shifts in factor intensity within firms (Ewit). It is positive if, on average, firms have substituted away from unskilled towards skilled workers. The second term gives the part of the total change that is attributable to the change in firms' relative size (the change in the employment share, $S^{i}$ ), keeping each firm's factor proportions constant at the period's averages. This reflects employment shifts between firms (Ebet). It is positive if employment has, on average, shifted towards skill-intensive firms.

Similarly, the (weighted) change in the non-manual relative wage can be decomposed as follows:

$$
\Delta\left(\frac{W_{n}}{W}\right)\left(\overline{\frac{E_{n}}{E}}\right)=\sum_{i}\left[\begin{array}{c}
\Delta D_{n}^{i} \overline{R^{i}} \\
{ }_{W i t} \\
\Delta R_{\text {Wbet }}^{i} \overline{D_{n}^{i}}
\end{array}\right]\left(\frac{E_{n}^{i}}{E}\right)
$$


where $D_{n}^{i}=\frac{W_{n}^{i}}{W^{i}}$ is the wage differential at firm $i$, and $R^{i}=\frac{W^{i}}{W}$ is the average wage at firm $i$ relative to the average economy-wide wage. The first term on the right hand side of the above expression is the change in non-manual relative wage that is attributable to the movement in the firms' wage premia, keeping constant their average wage. This is the wage within component (Wwit), and it is positive when, on average, firms pay larger premia. The second term is the component that is attributable to the change in firms' average wage rate, keeping each firm's wage premium constant. This is the between component ( Wbet), and it is positive if, on average, wages rise faster in firms that pay higher wage premia.

Summing up, within-firm components presumably reflect factor-specific shocks, such as a change in the relative productivity of skilled workers due to skill-biased technical progress. Between components reflect firm and sectorspecific shocks altering relative market shares or average wage rates. These may originate on either the demand side (e.g., changes in consumer tastes, trade) or the supply side (e.g., sector-biased technical change).

The results of the decomposition of equations (1-3) are presented in Table $3 .{ }^{12}$ Looking first at the change in relative employment (Etot), this appears to be very small over the period (an absolute change of 0.09). Interestingly, however, the virtual absence of change in factor proportions is the result of two offsetting forces: a 0.60 rise within firms (Ewit), and a half percent fall in the between component (Ebet). This suggests, on the one hand, that Italian manufacturing firms have raised the proportion of non manual employees at a speed comparable with that of the US (see Bernard and Jensen (1997)), but, on the other hand, that employment has shifted towards firms producing unskilled-intensive goods. ${ }^{13}$ These figures contrast quite markedly with the evidence found for the US and the UK, where both factors contribute positively to the overall movement in factor proportions. This, we believe, is an important finding, and it helps to explain the apparent rigidity of the labor market.

One possible explanation for the counter-intuitive effect of trade rests on

\footnotetext{
${ }^{12}$ Columns 1 to 3 of Table 3 reproduce, in terms of absolute changes, the movements in relative employment and wages reported in Table 1. Here, however, a smaller sample of firms is considered (those that are surveyed in 1995 and 1997).

${ }^{13} \mathrm{An}$ interesting illustration of this surprising effect is given by the Electronic Components and Machinery sub-sectors. The former, a skill-intensive industry, experiences a large fall in the employment share (see the negative between component of Table 3), while the latter, a relatively unskilled-intensive sector, a rise.
} 
the specialization pattern of Italian firms in vertical intra-industry trade. While it is well documented that Italian firms specialize in high-quality, high-skill segments in traditional sectors (apparel, footwear), there is evidence showing that in other sectors, markedly in mechanical productions, Italian exports are concentrated in relatively highly standardized segments (De Nardis and Traù (1999), Chiarlone, (2001)). ${ }^{14}$ As a consequence, trade shocks that magnify the relative market share of export-oriented firms may have contributed to keep a relatively flat structure of earnings across skill levels. Also, recall that Italy's comparative advantage has to be gauged with respect to its main trading partners (mostly European), rather than to the "world" at large.

Table 3 also reports the contribution of exporters and non-exporters to overall changes. Interestingly, exporters account disproportionately for both the (negative) between and the (positive) within-firm changes. Provided we can attribute the former to product demand shifts and the latter to technology, exporters seem to have innovated more, and demand seems to have shifted towards unskilled labor-intensive exports. Note that, as shown in Table 4, the disproportionate contribution of exporters to both components is confirmed within each size class, with the exception of small firms. Thus, as in Bernard and Jensen (1997), trade seems to play a crucial, albeit reversed, role in affecting factor proportions. Finally, looking at the role of labor institutions, labor conflict seems to magnify the employment shift away from skilled-intensive firms. Also, less conflict appears to be conducive to more innovation resulting in more skill-upgrading.

Consider now the change in the wage premium. This amounts to a fourth of a percentage point overall, and is almost equally divided between the two components: a rise of within-firm differentials, and a shift in wages towards firms paying larger premia. Also in this respect, exporters and non exporters present quite a different picture: only in exporting firms we observe a widening of the spread, as the wage within components are 0.14 and 0.01 for exporters and non-exporters, respectively.

It is interesting to observe that the employment and wage between components have opposite signs, negative the former and positive the latter, so that employment has shifted toward unskilled-intensive firms, but wages

\footnotetext{
${ }^{14}$ There is also evidence showing that vertical intra-industry trade is relevant and growing across European countries (see, e.g., Greenaway, Hine and Milner (1994) and Fontagnè, Freudenberg and Peridy (1997), (1998)).
} 
toward high premium firms. The explanation of this apparent contradiction is that, in our sample, unskilled-intensive firms pay, on average, higher wage premia, so that demand shifts towards these firms result in a rise in the wage premium.

Summing up, technical progress appears to have boosted the relative productivity of non-manual workers, resulting in both a larger employment share of skilled labor and in a higher wage premium, and particularly so among exporters. Conversely, the employment between component suggest that demand has shifted towards unskilled-intensive firms, and in particular, towards exporters.

\section{A finer decomposition}

In this section we disaggregate the class of non-manual workers into executives (quadri) and clerks (impiegati), and examine their respective contributions to the movements previously analyzed. Executives and clerks typically perform rather different tasks, so that we can expect a different degree of substitutability with manual workers. In particular, demand changes across firms as well as technological innovations may affect these two groups in a different way, so that one suspects that the standard aggregation into a single category may hide an important element of heterogeneity. The main finding of this section is that within changes in relative wages and employment, those related to technical progress, have mostly occurred between executives and clerks, rather than between manual and non-manual workers.

Let's consider employment first, and separate non-manual employment at firm $i$ into two classes: $E_{n}^{i}=E_{n_{1}}^{i}+E_{n_{2}}^{i}$. The (weighted) change of the non-manual employment share ( see (2)) can then be written as follows (see the appendix for details):

$$
\Delta\left(\frac{E_{n}}{E}\right) \overline{\left(\frac{W_{n}}{W}\right)}=\left[\text { Ewit }_{1}+\text { Ewit }_{2}\right]+\left[\text { Ebet }_{1}+\text { Ebet }_{2}\right]
$$

where Ewit $_{j}$ represents the within change in the non-manual employment share that is attributable to class $j$, and Ebet $_{j}$ gives the part of the between change in the non-manual employment share that is attributable to class $j$. Similarly, the weighted change in the non-manual relative wage (equation 3) 
can be written as follows:

$$
\Delta\left(\frac{W_{n}}{W}\right)\left(\overline{\frac{E_{n}}{E}}\right) \equiv\left[\text { wit }_{1}+\text { Wwit }_{2}\right]+\left[\text { Wbet }_{1}+\text { Wbet }_{2}\right]
$$

The results of these decompositions, presented in Table 5, are striking. Looking at the disaggregation of the employment share, we observe that the stable proportion of non-manual versus manual employees hides a large rise in the share of executives $(+0.7 \%)$ almost exactly offset by a fall of the clerks' contribution. These contrasting movements are largely attributable to the within components. Possibly due to technological change, firms have substituted away from clerks $(-0.52 \%)$ and towards highly-skilled workers $(+1.11 \%)$. It is interesting to note that this effect is quantitatively larger than the (within-firm) substitution from manual to non-manual workers found earlier.

Turning to the employment between changes, we observe that executives account for the largest part of the fall of this component. This means that the shift towards unskilled-intensive goods has mostly penalized firms producing executive-intensive products (compare the employment between entries for executives and clerks). It is interesting to observe that exporters account for most of the employment between changes for both sub-categories. Also, exporters have been more active than non-exporters in skill-upgrading by substituting away from clerks towards executives (compare the employment within entries for exporters and non exporters).

The results for the changes in wage premia are even more striking. They suggest that the relative wage rigidity in the face of technology shocks is merely an artifact of aggregation. The modest $0.26 \%$ rise in the wage premium is the result of two opposite forces: a very large rise in the premium of executives over the average wage rate, $0.96 \%$, and a large fall in the premium for clerks $(-0.71 \%)$. Interestingly, the rise in wage inequality is mostly accounted for by exporting, large, northern firms.

In order to facilitate the comparison with the literature, in Table 9 we also report the results for the standard decompositions (e.g. not weighted by employment, see the Appendix). These results are even stronger: the relative wage of executives rises by 5.04 per cent and that of clerks falls by 4.45 per cent.

These findings support the conclusion that technology-related changes have indeed occurred in Italy and have had noticeable consequences on both factor prices and factor shares. However, the rise in wage inequality and 
the skill upgrading that are attributable to technology have occurred within non-manual workers, rather than between manual and non-manual workers. ${ }^{15}$

\section{$6 \quad$ Interpreting the components}

So far we have loosely interpreted the within and between components as proxies for technology and demand shocks, respectively. In this section we provide a test of the legitimacy of this interpretation. We regress the employment and wage between and within components on a number of variables that are intended to capture demand, trade, and technology shocks affecting individual firms. If our interpretation is correct, within changes should be significantly correlated to technology but not to demand variables, while the converse should be true for between changes.

As indicators of demand shocks, we use the change in the ratio of a firm's sales over total sales, and we split this variable into its domestic (Domsale) and foreign (Forsale) components. In order to capture technological change and innovation activity occurring at firm level, we use the average (1995-97) ratio of investment over sales, considering separately its three components. The first, Invnew, is the share of investment for the production of new products: this is supposed to capture "product" innovation. The second, Invris is the share of investment for restructuring and reconverting existing production lines, presumably capturing "process" innovation. Finally, Invamp measures outlays for merely enlarging existing production lines. This variable is more difficult to interpret as a proxy for technological change, as it may equally plausibly reflect expectations of growing demand. We also include the change in the firm's revenue per employee, Salepw, in order to account for factors affecting changes in productivity.

Labor market institutions are accounted for by a series of dummy variables that control for the presence/absence of unionized workers in the firm, the role of the union in local bargaining, and the occurrence/not occurrence of strikes. Finally, we employ a dummy variable for outsourcing (which may be relevant if firms outsource the most un-skilled intensive phases of production), a proxy of geographical location (the number of firms operating in the same area code), size (small, medium, large), and sub-sectors (as described in Table 1).

\footnotetext{
${ }^{15}$ Evidence supporting the view that wage dispersion in Italy has been growing especially within skills is provided also in other studies, see, e.g. Cappellari (2000).
} 
Table 6 reports OLS estimates of the equations for the wage bill share, and the respective contributions of the employment ratio and the wage premium. The between change in relative employment, Ebet is positively and significantly correlated to domestic (Domsale) and foreign (Forsale) sales growth, with the coefficient for the latter larger than that for the former. Our proxies for product and process innovation (Invnew and Invrist), as expected, are not statistically significant. Conversely, the within employment change, Ewit, is positively and significantly affected by product innovation and by our proxy for productivity growth (Salepw). This pattern broadly supports our maintained assumption that demand/trade on the one hand, and technology, on the other, lie behind between and within employment changes, respectively.

The results for wage premia are less clear-cut. Domestic and foreign sales are significant in both between and within wage equations. The negative effect on the between wage component could be interpreted as a reverse causation: firms who manage to reduce their average wage gain in competitiveness and increase their market share. A possible interpretation of the positive effect on the within component is the "superstar" effect for exporters discussed in Manasse and Turrini (2001).

The equations for the non-manual share of the wage bill present a similar pattern to the employment equations: domestic and foreign sales affect positively and significantly the between component. Investment in plant for new products is positive and marginally significant for both between and within components.

Interestingly, the proxies for labor market institutions, trade, location, and industry, are never significant in the relative employment and wage equations: the standard proxies for labor market rigidities do not seem to slow down firms' adjustment of relative factor proportions and prices.

It should be noted that the results for similar regressions for the unweighted components, reported in Table 10, confirm the pattern described for the weighted components. ${ }^{16}$ Overall these results, particularly those for the dynamics of employment, are supportive of our interpretation that between and within components are associated with demand and technology shocks.

\footnotetext{
${ }^{16}$ Note also that the results of Tables 6 and 10 are qualitatively and quantitatively similar to those reported in the literature (see e.g. Bernard and Jensen (1997)).
} 


\section{Conclusions}

In this paper we have presented firm level evidence on the dynamics of nonmanual wage premia and employment shares in Italian manufacturing in the nineties. The "puzzle" of the modest change in relative factor prices and employment shares in a period of rapid technological change and trade integration cannot be explained away by advocating the "rigidity" of the labor market.Our first finding is that technology and trade have indeed significantly affected wage premia and factor proportions. What seems to have happened is that "IT" and "globalization" forces have largely offset each other. Technical progress is found to raise, as expected, the relative demand for non-manual labor within firms. However, demand changes associated with exports surprisingly reduce the relative demand for skills: employment has shifted towards firms producing unskilled-intensive goods, offsetting the effect of technology upon factor proportions and wage shares.

Our second finding is that flat relative wage premia and employment shares are largely an artifact of aggregation. When we look within the category of non-manual workers, we find a large rise in the wage premium and employment share of executives, and a considerable fall in the wage premium and employment share of clerks. In Italy, the rise in wage inequality and in skill upgrading that are attributable to technology seem to have occurred within the category of non-manual workers, rather than between manual and non-manual workers.

We also find evidence suggesting that the export status of firms matters substantially in explaining the labor market shifts that occurred halfway through the past. In particular, Italian exporters account for a disproportionate role in both demand-related and technology-related shifts. On one hand, demand has been shifting towards unskilled-intensive exporting firms. However, these firms have most intensively engaged into skill upgrading.

Finally, institutional factors such as union power and centralized bargaining, typically associated to labor market "rigidities", are found not to slow down significantly the adjustment of relative factor prices and shares.

These conclusions need to be kept in perspective. They apply only to one sector of Italian manufacturing, although the largest one in terms of value added and exports. They apply to a relatively short period, although one of rapid growth in investment and exports. Obviously, they cannot be taken as representative of a "continental European" case. Yet we feel that these results, interesting in their own merit, underscore the need to assess 
the merits of conventional explanations for aggregate outcomes on the basis of sound microeconomic evidence. 


\section{Appendix}

This appendix provides details on the decompositions presented in the main text. We start by identifying the contributions of employment and wages to the change in the non-manual share of the wage bill, and we show hot to identify separately the respective between and within components. We then illustrate how these weighted components differ from the unweighted decompositions of the change in the wage premium and the change in the nonmanual employment share commonly reported in the literature. Finally, we show how to exploit the disaggregate information contained in our database to decompose the overall between and within components for non-manual workers into the respective contributions of clerks and executives.

Let there be $i=1, \ldots, I$ firms, and define $E^{i}=$ employment at firm $i$, $E_{n}^{i}=$ non-manual employment at firm $i, E=\sum_{i} E^{i}=$ overall employment, $E_{n}=\sum_{i} E_{n}^{i}=$ overall non-manual employment, $W^{i}=\frac{\sum W^{i} E^{i}}{\sum E^{i}}=$ average wage at firm $i, W_{n}^{i}=\frac{\sum W_{n}^{i} E_{n}^{i}}{\sum E_{n}^{i}}=$ average non-manual wage at firm $i, W=$ $\frac{\sum W^{i} E^{i}}{\sum E^{i}}$ economy-wide average wage rate, $W_{n}=\frac{\sum W_{n}^{i} E_{n}^{i}}{\sum E_{n}^{i}}=$ economy-wide average non-manual wage rate.

The change in the non-manual share of the total wage bill, $W_{n} E_{n} / W E$, can be written as follows:

$$
\begin{aligned}
& \Delta\left(\frac{W_{n} E_{n}}{W E}\right)=\Delta\left(\frac{W_{n}}{W}\right)\left(\overline{\frac{E_{n}}{E}}\right)+\Delta\left(\frac{E_{n}}{E}\right)\left(\overline{\frac{W_{n}}{W}}\right)
\end{aligned}
$$

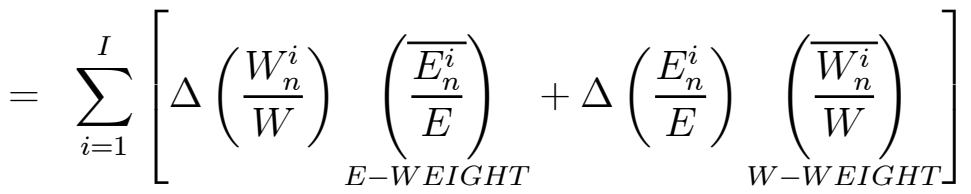

where $\Delta$ denotes differences between two points in time, and the upper bar on variables denotes averages over time. The first term on the right hand side of the last expression is the component attributable to the change in the wage differentials, keeping constant the employment structure over time. It is positive (negative) if, on average, an increase (decrease) in the relative wage for skilled workers has occurred. The second term gives the change associated with movements in relative employment, at constant relative wages. It is positive (negative) if, on average, the relative employment of non-manual workers has risen (fallen). 
However, the information emerging from the previous decomposition cannot tell us whether, for example, higher employment shares for non-manual workers are due to the fact that firms have become more skill-intensive or to the fact that the employment has shifted toward skill-intensive firms. Similarly, higher wage differentials may be due to the fact that firms have paid higher skill premia or to the fact that average wages have mostly risen in firms paying relatively high skill premia. In order to answer such questions we can decompose further the expression above identifying separately between and within components. To this purpose, note that the relative wage bill can be written as follows:

$$
\begin{aligned}
\frac{W_{n} E_{n}}{W E} & =\sum_{i}^{I}\left(\frac{W_{n}^{i} E_{n}^{i}}{W E}\right)=\sum_{i}^{I}\left(\frac{W_{n}^{i}}{W^{i}} \frac{W^{i}}{W} \frac{E_{n}^{i}}{E^{i}} \frac{E^{i}}{E}\right) \\
& =\sum^{I}\left(D_{n}^{i} R^{i} P_{n}^{i} S^{i}\right)
\end{aligned}
$$

where $D_{n}^{i}=\frac{W_{n}^{i}}{W^{i}}$ is wage differential at firm $i, R^{i}=\frac{W^{i}}{W}$ is relative wage at firm $i$ relative to the economy-wide rate, $P_{n}^{i}=\frac{E_{n}^{i}}{E^{i}}$ is the proportion of skilled employment at firm $i, S^{i}=\frac{E^{i}}{E}$ is the employment share of firm $i$. Intuitively, the overall relative wage bill is sum over all firms of the product of four conceptually distinct components: the wage premium paid to non-manual workers by firm $i\left(D_{n}^{i}\right)$; the wage rate at firm $i$ relative to the overall wage rate $\left(R^{i}\right)$; the share of non-manual workers at firm $i\left(P_{n}^{i}\right)$; the share of firm $i$ 's employment out of overall employment $\left(S^{i}\right)$.

To analyze the sources of dynamics, take time-differences and decompose the change in the overall relative wage bill as follows:

$$
\begin{aligned}
& \Delta\left(\frac{W_{n} E_{n}}{W E}\right)=\sum_{i}^{I} \Delta\left(D_{n}^{i} R^{i} P_{n}^{i} S^{i}\right)=\sum_{i}^{I}\left[\Delta\left(D_{n}^{i} R^{i}\right) \overline{P_{n}^{i} S^{i}}+\Delta\left(P_{n}^{i} S^{i}\right) \overline{D_{n}^{i} R^{i}}\right]
\end{aligned}
$$

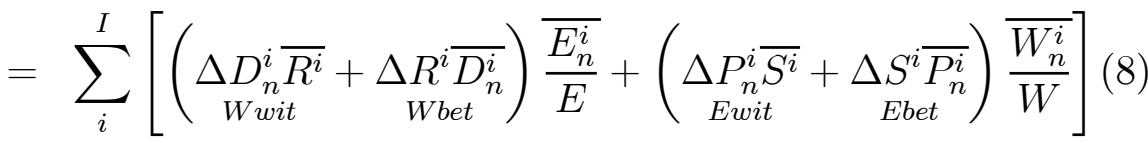

Expression (8) decomposes the contributions of relative wages and employment shares to the change in the non-manual wage-bill share into the respective components capturing between-firm and within-firm dynamics. Note that these four components are weighted by the corresponding employment 
and wage weights. These weighted components (reported in Tables 3-6) thus differ from their unweighted counterparts (reported in Tables 7-10), given by the between and within components of the change in the non-manual employment and wage bill shares.

To illustrate the differences, we now consider separately the change in the employment share of non manual-workers $\Delta\left(\frac{E_{n}}{E}\right)$ and the change in the non-manual wage premium $\Delta\left(\frac{W_{n}}{W}\right)$, decomposing each of them into a component capturing movements between different firms, and one associated with changes within the individual firm.

Consider first the decomposition of the change in relative employment:

$$
\begin{aligned}
\Delta\left(\frac{E_{n}}{E}\right) & =\Delta \sum_{i} \frac{E_{n}^{i}}{E}=\Delta \sum_{i} \frac{E_{n}^{i}}{E^{i}} \frac{E^{i}}{E}= \\
& =\Delta \sum_{i} P_{n}^{i} S^{i}= \\
& =\sum_{i}\left[\begin{array}{l}
\Delta P_{n}^{i} \overline{S^{i}}+\underset{E-W I T}{\Delta} S^{i} \overline{P_{n}^{i}} \\
E-B E T
\end{array}\right]
\end{aligned}
$$

The first term is the change in the non-manual employment share that is attributable to the change in the firms' factor proportions, $P_{n}^{i}$, keeping constant their relative size. This reflects shifts in factor intensity within plants. It is positive if skill upgrading has occurred in larger firms. The second term gives the part of the total change in the non-manual employment share that is attributable to the change in plant relative size (the change in the employment share, $S^{i}$ ), keeping each firm's factor proportions constant at the period's average. This reflects employment shifts between firms. It is positive if employment rises relatively more in skill-intensive plants.

Consider now the decomposition of the changes in wage differentials:

$$
\begin{aligned}
\Delta\left(\frac{W_{n}}{W}\right) & =\Delta \frac{\sum_{i} W_{n}^{i} E_{n}^{i}}{W E_{n}}=\Delta \sum_{i} \frac{W_{n}^{i}}{W^{i}} \frac{W^{i}}{W} \frac{E_{n}^{i}}{E_{n}}= \\
& =\Delta \sum_{i} D_{n}^{i} R^{i} S_{n}^{i} \\
& =\sum_{i}\left[\begin{array}{c}
\Delta D_{n}^{i} \overline{R^{i}} \overline{S_{n}^{i}}+\Delta R^{i} \overline{D_{n}^{i}} \overline{S_{n}^{i}}+\Delta S_{n-B T}^{i} \overline{D_{n}^{i}} \overline{R^{i}} \\
W-B E T
\end{array}\right]
\end{aligned}
$$


where $S_{n}^{i}=\frac{E_{n}^{i}}{E_{n}}$ is firm's i share of non-manual employment. The first term is the within component, and it is positive (negative), when the wage gap rises (falls) on average within firms. The second term is the relative wage change occurring between firms. It is positive when, on average, wages have been rising faster in firms that pay higher wage premia. The third term is another between component, reflecting changes in the composition between firms of non-manual employment. It is positive when, on average, non-manual employment shares rise more in firms that pay higher wage premia.

Summing up, the non-manual employment share and relative wage can rise for two reasons. Relative skilled employment can rise either because on average firms employ more skilled workers or because total employment increases in firms that have an employment structure biased in favour of skilled labor. The wage gap may rise either because on average firms pay higher differentials or because wages rise relatively faster in those firms paying higher wage premia. The within components presumably reflect factorspecific shocks, such as a change in the relative productivity of skilled workers due to skill-biased technical progress. The between components reflect firm and sector-specific shocks altering relative market shares that may have both a demand (e.g., trade, changes in consumer tastes) or a supply origin (e.g., firm-biased neutral technical change).

Let's now turn to the decomposition of the contributions of non-manual workers into those of clerks and executives. In general, if the data set allows a finer decomposition of non-manual employment in $K$ classes, the decompositions presented above can be extended to present the respective contributions of each class (e.g. clerks and managers) to the overall non-manual dynamics. Assume that non-manual employment at firm $i$ can be divided into $k=1,2, \ldots K$ categories:

$$
E_{n}^{i}=E_{1}^{i}+E_{2}^{i}+\ldots+E_{K}^{i}
$$

and define the $k$ factor intensity as $P_{k}^{i}=\frac{E_{k}^{i}}{E^{i}}$. Note also that we can write

$$
W_{n}^{i}=\frac{\sum_{k} W_{k}^{i} E_{k}^{i}}{E_{n}^{i}}=\sum_{k} W_{k}^{i} \pi_{k}^{i}
$$

where $\pi_{k}^{i}=\frac{E_{k}^{i}}{E_{n}^{i}}$ is class' $k$ share of non-manual employment at firm $i$.

Consider first the contribution of each of the $K$ classes to each of the components of the wage bill decomposition: 


$$
\sum_{i}^{I}\left[\left(\Delta D_{n}^{i} \overline{R^{i}}+\Delta R^{i} \overline{D_{n}^{i}}\right)\left(\overline{P_{n}^{i} S^{i}}\right)+\left(\Delta P_{n}^{i} \overline{S^{i}}+\Delta S^{i} \overline{P_{n}^{i}}\right)\left(\overline{D_{n}^{i} R_{n}^{i}}\right)\right]
$$

The first term (wage within) can be written as: ${ }^{17}$

$$
\begin{aligned}
\sum_{i}\left[\Delta D_{n}^{i} \overline{R^{i}} \overline{P_{n}^{i} S^{i}}\right] & = \\
& =\sum_{i} \sum_{k}\left[\Delta\left(D_{k}^{i} \pi_{k}^{i}\right) \overline{R^{i}}\left(\overline{P_{n}^{i} S^{i}}\right)\right]= \\
& =\sum_{k} \sum_{i}\left[\left(\Delta D_{k}^{i} \overline{\pi_{k}^{i}}+\Delta \pi_{k}^{i} \overline{D_{k}^{i}}\right)\left(\overline{R^{i}} \overline{P_{n}^{i} S^{i}}\right)\right]
\end{aligned}
$$

Similarly, the other components can be written as follows:

$$
\begin{gathered}
\sum_{i}\left[\Delta R^{i} \overline{D_{n}^{i}}\left(\overline{P_{n}^{i} S^{i}}\right)\right]=\sum_{k} \sum_{i}\left[\Delta R^{i} \overline{D_{k}^{i} \pi_{k}^{i}} P_{n}^{i} S^{i}\right]=\sum_{k} \sum_{i}\left[\Delta R^{i} \overline{D_{k}^{i} P_{k}^{i} S^{i}}\right] \\
\sum_{i}\left[\Delta P_{n}^{i} \overline{S^{i} D_{n}^{i} R^{i}}\right]=\sum_{k} \sum_{i}\left[\Delta P_{k}^{i} \overline{S^{i}} \overline{D_{n}^{i} R^{i}}\right] \\
\sum_{i}\left[\Delta S^{i} \overline{P_{n}^{i} D_{n}^{i} R^{i}}\right]=\sum_{k} \sum_{i}\left[\Delta S^{i} \overline{P_{n}^{i}} \overline{D_{k}^{i} \pi_{k}^{i} R^{i}}\right]=\sum_{k} \sum_{i}\left[\Delta S^{i} \overline{P_{k}^{i}} \overline{D_{k}^{i} R^{i}}\right]
\end{gathered}
$$

Note that

$$
\begin{aligned}
\frac{W_{n} E_{n}}{W E} & =\sum_{i} \frac{W_{n}^{i} E_{n}^{i}}{W E}=\sum_{k} \sum_{i} \frac{W_{k}^{i} E_{k}^{i}}{W E}=\sum_{k} \sum_{i}\left(D_{k}^{i} R^{i} P_{k}^{i} S^{i}\right)= \\
& =\sum_{k} \sum_{i}\left(D_{k}^{i} R^{i} \pi_{k}^{i} P_{n}^{i} S^{i}\right)
\end{aligned}
$$

\footnotetext{
${ }^{17}$ Note that the first term is equal to what we would obtain by summing over classes the individual within component. Intuitively, by doing so, we would not take into account the changes in within non-manual wages due to the recomposition of employment between classes within non-manual.
} 
Turning to the contribution of individual classes to the decomposition of the change in relative employment:

$$
\Delta P_{n}=\Delta \sum_{i} P_{n}^{i} S^{i}=\Delta \sum_{i} \sum_{k} P_{k}^{i} S^{i}
$$

and one can write

$$
\Delta P_{n}=\sum_{k=1}^{K}\left[\sum_{i=1}^{I}\left(\Delta S^{i} \bar{P}_{k}^{i}+\Delta P_{k}^{i} \overline{S^{i}}\right)\right]
$$

where, as before, $\bar{P}_{k}^{i}=\frac{P_{k}^{i}(0)+P_{k}^{i}(1)}{2}$ represents the average k-factor intensity at firm i.

In summary, the previous expression simply states that between/within components of the share of non manual workers is simply given by the sum of the corresponding between/within components of the sub-classes $k=1, \ldots, K$ (e.g. clerks, managers).

Finally, consider the contribution of individual classes to the decomposition of the change in the wage differential:

$$
\begin{aligned}
\Delta \frac{W_{n}}{W} & =\Delta \sum_{i}\left(D_{n}^{i} R^{i} S_{n}^{i}\right)= \\
& =\sum_{k} \sum_{i}\left(D_{k}^{i} \pi_{k}^{i} R^{i} S_{n}^{i}\right)
\end{aligned}
$$

From the previous expression we obtain:

$$
\begin{gathered}
\sum_{i}\left[\Delta D_{n}^{i} \overline{R^{i}} \overline{S_{n}^{i}}\right]=\sum_{k} \sum_{i}\left[\left(\Delta D_{k}^{i} \overline{\pi_{k}^{i}}+\Delta \pi_{k}^{i} \overline{D_{k}^{i}}\right)\left(\overline{R^{i}} \overline{S_{n}^{i}}\right)\right] \\
\sum_{i}\left[\Delta R^{i} \overline{D_{n}^{i}} \overline{S_{n}^{i}}\right]=\sum_{k} \sum_{i} \Delta R^{i} \overline{D_{k}^{i} \pi_{k}^{i}} \overline{S_{n}^{i}} \\
\sum_{i}\left[\Delta S_{n}^{i} \overline{D_{n}^{i}} \overline{R^{i}}\right]=\sum_{k} \sum_{i}\left[\Delta S_{k}^{i} \overline{D_{n}^{i}} \overline{R^{i}}\right]
\end{gathered}
$$

where $S_{k}^{i}=\frac{E_{k}^{i}}{E_{n}}$. 


\section{References}

[1] Bernard, A.B. and J.B. Jensen, 1995, Exporters, jobs and wages in U.S. manufacturing: 1976-1987, Brookings Papers on Economic Activity: Microeconomics, 67-119.

[2] Bernard, A.B. and J.B. Jensen, 1997, Exporters, skill upgrading, and the wage gap, Journal of International Economics, 42, 3-31.

[3] Bernard, A.B. and J.B. Jensen, 1999, Exceptional exporter performance: cause, effect, or both?, Journal of International Economics,47, 1-25.

[4] Bernard, A.B., J. Eaton, J.B. Jensen, and S. Kortum, 2000, Plants and productivity in international trade, NBER Working Paper No. 7135.

[5] Black, S. E., and L. Lynck, 2000, What' s driving the New Economy: the benefits of workplace innovation, NBER Working Paper No. 7479.

[6] Borjas, G. J., R. Freeman, and L. Katz, On the labor-market effects of immigration and trade, in G. Borjas and R. Freeman (eds.) Immigration and the Work Force, Chicago: University of Chicago Press, 1992, 213-44.

[7] Cappellari, L., 2000, The covariance structure of Italian male wages, Manchester School, 68, 659-84.

[8] Card, D., Kramarz, F., and T. Lemieux (1998), Changes in the relative structure of wages and employment: a comparison of Canada, France and the United States, CEPR Working Paper No. 2008.

[9] Chiarlone. S., 2001, Evidence of product differentiation and relative quality in Italian trade, CESPRI Working Paper No. 114, forthcoming in Rivista Italiana degli Economisti.

[10] Clerides, S., S. Lauch and J. Tybout, 1998, Is learning by exporting important? The Quarterly Journal of Economics, 454, 903-47.

[11] Daveri, F., 2001, Information technology and growth in Europe, IGIER, mimeo.

[12] Dell' Aringa, C., and C. Lucifora, 1994, Collective bargaining and relative earnings in Italy, European Journal of Political Economy, 10, 727-47. 
[13] Dell' Aringa, C., and C. Lucifora, 2000, Inside the black box: Labour market institutions, wage formation and unemployment in italy, Rivista di Politica Economica, 90, 13-55.

[14] De Nardis, S., and F. Traù, 1999, Specializzazione settoriale e qualità dei prodotti: misure della pressione competitiva sull' industria italiana, Rivista Italiana degli Economisti, 2.

[15] Erikson, C. and A. Ichino, 1995, Wage differentials in Italy. Market forces, institutions and inflation. in R. Freeman and L. Katz (eds.), Differences and Changes in the Wage Structure, NBER-University of Chicago Press.

[16] Federmeccanica, 2000, "Indagine Annuale", http://www.federmeccanica.it/pubb/f02a.html

[17] Feenstra, R., and G. Hanson, 1999, The impact of outsourcing and hightechnology capital on wages: estimates for the US, 1972-1990, Quarterly Journal of Economics, 114, 907-40.

[18] Ferragina, A. M., and B. Quintieri, 2000, Caratteristiche delle imprese esportatrici italiane. Un' analisi su dati Mediocredito e Federmeccanica, ICE, Quaderno di Ricerca No. 14.

[19] Fontagnè, L., M. Freudenberg, N. Peridy, 1997, Trade Patterns inside the Single Market, Kogan Page: London.

[20] Fontagnè, L., M. Freudenberg, N. Peridy, 1998, Intra-industry trade and the sigle market: quality matters, CEPR Discussion Paper No. 1959.

[21] Freeman, R. and L. Katz, 1996, Introduction and summary, in R. Freeman and L. Katz, (eds.) Differences and Changes in Wage Structure, The University of Chacago Press, Chicago.

[22] Greenaway, D., R. Hine and C. Milner, 1994, Country-specific factors and the patttern of horizontal and vertical intra-industry trade in the UK, Welwirtschaftliches Aarchives 130, 77-99.

[23] Jorgenson, D. W., and K. J. Stiroh, 2000, Raising the speed limit: US economic growth in the information age, Brookings Papers on Economic Activity, 125-235. 
[24] Krugman, Paul R., 1995, "Technology, Trade and Factor Prices", NBER Workin Paper 5355

[25] Haskel, J. 2000, Trade and Labor Approaches to Wage Inequality, Review of International Economics, 8(3), 397-408.

[26] Haskel, J., and M. Slaughter, 2001a, Trade, technology, and UK wage inequality, Economic Journal, 110, 163-87.

[27] Haskel, J., and M. Slaughter, 2001b, Does the sector bias of skill-biased technological change explain changing skill premia?, European Economic Review, forthcoming.

[28] Leamer, E., 1998, In search of Stolper-Samuelson effects on US wages, in S. Collins (ed.), Exports, Imports, and the American Worker, Washington D.C.: The Brookings Institution.

[29] Lucifora, C., 1995, Determinazione del salario in Italia: una rassegna della letteratura empirica. Il contributo dell' analisi dei micro-dati, in

[30] Machin, S., Berman, E. and J. Bound, 1998, Implications of Skill-Biased Technological Change: International Evidence, Quarterly Journal of Economics, 113, 1245-79.

[31] Machin, S. and J. Van Reenen, 1998, Technology and Changes in Skill Structure: Evidence From Seven OECD Countries, Quarterly Journal of Economics, 113, 1215-44.

[32] Manasse, P. and A. Turrini, 2001, Trade, wages, and superstars, Journal of International Economics, 54, 97-117.

[33] OECD, 1996, Employment Outlook, OECD, Paris.

[34] OECD, 1997, Trade, earnings and employment: assessing the impact of trade with emerging economies on OECD labour markets", in Employment Outlook, OECD, Paris.

[35] Oliner, S., and D. Sichel, 2000, The resurgence of growth in the late 1990s: is information technology the story?, Journal of Economic Perspectives, 14, 3-22. 
[36] Quintieri, B., and F.C. Rosati, 1995, Employment structure, technological change and international trade: the Italian manufacturing sector in the eighties, in B. Quintieri (ed.), Patterns of Trade, Competition and Trade Policies, Avebury, 133-155.

[37] Richardson, J., 1995, Income Inequality and Trade: How to Think, What to Conclude, Journal of Economic Perspectives, 9(3), 33-55.

[38] Slaughter, M., 1998, International trade and labour market outcomes: results, oucomes, and policy options, The Economic Journal, 110, 163187.

[39] Slaughter, M., 1999, Globalization and wages: a tale of two perspectives, The World Economy, 22, 609-30.

[40] Wood, A., 1995, How Trade Hurt Unskilled Workers, Journal of Economic Perspectives, 9(3), 57-80. 
Table 1: Means for selected variables: overall and by sub-sample

\begin{tabular}{|c|c|c|c|c|c|c|c|c|}
\hline Sample & WBnWB & $\overline{\mathrm{WnW}}$ & EnE & $\mathrm{Wn}$ & W & En & $\mathrm{E}$ & N.Obs. \\
\hline Overall & 36.9 & 120.2 & 32.0 & 3013.9 & 2507.2 & 49.6 & 152.3 & 8148 \\
\hline 1995 & 36.8 & 119.6 & 32.1 & 2886.2 & 2411.0 & 49.9 & 152.4 & 2837 \\
\hline 1996 & 36.5 & 120.6 & 31.6 & 3004.4 & 2488.0 & 45.8 & 144.9 & 2612 \\
\hline 1997 & 37.3 & 120.3 & 32.4 & 3154.9 & 2624.6 & 52.8 & 159.5 & 2699 \\
\hline Small & 35.8 & 114.4 & 32.4 & 2810.9 & 2443.3 & 3.8 & 12.2 & 3323 \\
\hline Medium & 36.0 & 122.3 & 30.7 & 3055.3 & 2506.0 & 16.0 & 51.2 & 3015 \\
\hline Large & 40.2 & 125.4 & 33.7 & 3251.5 & 2611.9 & 189.6 & 578.2 & 1810 \\
\hline North & 36.9 & 120.4 & 32.0 & 3017.6 & 2506.3 & 50.3 & 154.3 & 6589 \\
\hline Centre & 37.3 & 119.2 & 32.5 & 3020.4 & 2532.1 & 46.4 & 136.5 & 1384 \\
\hline South & 31.8 & 120.0 & 27.6 & 2821.9 & 2340.6 & 46.7 & 205.6 & 175 \\
\hline Metal & 28.4 & 123.6 & 23.6 & 3009.4 & 2422.9 & 20.4 & 88.4 & 1780 \\
\hline Machinery & 36.8 & 119.6 & 31.6 & 3043.1 & 2543.3 & 30.4 & 96.9 & 2662 \\
\hline Precision & 54.9 & 114.3 & 50.2 & 3078.3 & 2704.0 & 155.4 & 217.9 & 342 \\
\hline Electrical & 47.9 & 120.1 & 42.1 & 3040.4 & 2546.5 & 97.9 & 245.8 & 877 \\
\hline Transport & 32.3 & 126.5 & 26.7 & 3096.0 & 2450.4 & 140.5 & 598.3 & 714 \\
\hline Other & 38.3 & 116.1 & 34.6 & 2909.2 & 2501.0 & 26.7 & 61.4 & 1773 \\
\hline Exporter & 38.3 & 121.7 & 32.7 & 3081.3 & 2536.8 & 67.0 & 208.0 & 5188 \\
\hline Non exp. & 34.3 & 117.4 & 30.7 & 2884.8 & 2452.3 & 18.8 & 53.4 & 2930 \\
\hline Union & 36.2 & 122.7 & 30.7 & 3106.9 & 2538.9 & 69.4 & 214.1 & 5571 \\
\hline No union & 38.5 & 114.2 & 34.9 & 2790.9 & 2433.6 & 6.6 & 18.8 & 2562 \\
\hline Strike & 35.7 & 124.6 & 29.7 & 3188.8 & 2565.5 & 111.8 & 345.1 & 2417 \\
\hline No strike & 37.3 & 118.2 & 33.0 & 2935.1 & 2481.1 & 22.9 & 68.9 & 5691 \\
\hline Outs. & 35.9 & 118.8 & 31.6 & 2967.1 & 2491.3 & 31.7 & 93.7 & 3289 \\
\hline No outs. & 37.5 & 121.2 & 32.2 & 3045.7 & 2515.6 & 62.2 & 193.6 & 4753 \\
\hline
\end{tabular}


Table 2: Means for selected variables by size

\begin{tabular}{lcccccccc}
\hline \hline Sample & WBnWB & WnW & EnE & Wn & W & En & E & N.Obs. \\
\hline Small & & & & & & & & \\
Exporter & 38.9 & 115.0 & 35.0 & 2853.4 & 2474.0 & 4.3 & 13.0 & 1526 \\
Non exp. & 33.2 & 113.9 & 30.2 & 2773.7 & 2417.5 & 3.3 & 11.5 & 1787 \\
Union & 31.8 & 117.4 & 28.1 & 2903.9 & 2467.1 & 4.0 & 14.3 & 1322 \\
No union & 38.2 & 112.5 & 35.1 & 2749.9 & 2427.3 & 3.6 & 10.8 & 1991 \\
Strike & 28.3 & 119.1 & 24.4 & 2935.4 & 2441.3 & 3.4 & 13.8 & 286 \\
No strike & 36.3 & 114.1 & 33.0 & 2801.3 & 2443.3 & 3.8 & 12.1 & 3020 \\
& & & & & & & & \\
Medium & & & & & & & & \\
Exporter & 37.1 & 122.6 & 31.3 & 3090.7 & 2526.7 & 16.8 & 53.1 & 2104 \\
Non exp. & 33.3 & 121.5 & 29.0 & 2970.7 & 2455.1 & 13.9 & 46.8 & 894 \\
Union & 35.4 & 123.0 & 29.9 & 3088.9 & 2518.2 & 16.3 & 53.4 & 2471 \\
No union & 38.5 & 119.0 & 34.0 & 2900.5 & 2448.7 & 14.3 & 41.0 & 539 \\
Strike & 34.2 & 124.2 & 28.5 & 3144.6 & 2537.4 & 16.7 & 57.0 & 1012 \\
No strike & 36.8 & 121.3 & 31.7 & 3010.5 & 2489.6 & 15.5 & 48.2 & 1991 \\
& & & & & & & & \\
Large & & & & & & & & \\
Exporter & 39.4 & 125.9 & 32.7 & 3256.1 & 2604.0 & 196.2 & 608.2 & 1558 \\
Non exp. & 45.1 & 122.6 & 40.1 & 3222.4 & 2662.7 & 147.2 & 377.6 & 249 \\
Union & 40.0 & 125.5 & 33.5 & 3254.8 & 2613.4 & 191.8 & 586.0 & 1778 \\
No union & 49.6 & 123.7 & 43.8 & 3067.8 & 2527.4 & 62.9 & 140.2 & 32 \\
Strike & 38.6 & 126.1 & 31.9 & 3277.8 & 2616.5 & 225.5 & 690.3 & 1119 \\
No strike & 42.7 & 124.3 & 36.6 & 3207.4 & 2605.4 & 129.2 & 382.0 & 680 \\
\hline
\end{tabular}

Note: $\mathrm{WBnWB}=$ non-manual share of wage bill; $\mathrm{WnW}=$ non-manual relative wage;

$\mathrm{EnE}=$ non-manual employment share; $\mathrm{Wn}=$ average non-manual wage;

$\mathrm{W}=$ average wage; $\mathrm{En}=$ non-manual employment; $\mathrm{E}=$ employment. Small: $\mathrm{E}<25$,

Large: $\mathrm{E}>100$. Exporter: Exp/Sales $>.01$. Union: presence of union members.

Strike: strikes occurred. 
Table 3: Decompositions of the non-production wage bill share

\begin{tabular}{|c|c|c|c|c|c|c|c|c|}
\hline Sample & WBtot & Etot & Wtot & Ebet & Ewit & Wbet & Wwit & N.Obs. \\
\hline Overall & 0.34 & 0.09 & 0.26 & -0.51 & 0.60 & 0.11 & 0.15 & 1518 \\
\hline Small & -0.02 & -0.05 & 0.03 & -0.08 & 0.03 & 0.03 & -0.00 & 512 \\
\hline Medium & 0.12 & 0.06 & 0.06 & -0.07 & 0.14 & 0.04 & 0.01 & 591 \\
\hline Large & 0.24 & 0.07 & 0.17 & -0.36 & 0.43 & 0.03 & 0.14 & 415 \\
\hline North & 0.30 & 0.07 & 0.23 & -0.51 & 0.58 & 0.13 & 0.11 & 1261 \\
\hline Centre & 0.04 & 0.03 & 0.01 & -0.02 & 0.05 & -0.02 & 0.03 & 234 \\
\hline South & 0.00 & -0.01 & 0.01 & 0.02 & -0.03 & -0.00 & 0.01 & 23 \\
\hline Metal & -0.01 & -0.04 & 0.03 & -0.09 & 0.06 & 0.04 & -0.00 & 312 \\
\hline Machin. & 0.45 & 0.26 & 0.19 & 0.08 & 0.18 & 0.12 & 0.07 & 528 \\
\hline Precis. & -0.00 & -0.03 & 0.03 & 0.01 & -0.04 & -0.00 & 0.03 & 56 \\
\hline Electr. & -0.23 & -0.25 & 0.02 & -0.46 & 0.21 & -0.03 & 0.05 & 166 \\
\hline Transp. & -0.02 & -0.00 & -0.02 & -0.01 & 0.01 & -0.06 & 0.03 & 143 \\
\hline Other & 0.16 & 0.15 & 0.01 & -0.04 & 0.19 & 0.04 & -0.03 & 313 \\
\hline Exporter & 0.20 & 0.01 & 0.19 & -0.41 & 0.41 & 0.05 & 0.14 & 825 \\
\hline Non exp. & 0.14 & 0.08 & 0.07 & -0.10 & 0.18 & 0.05 & 0.01 & 693 \\
\hline Union & 0.39 & 0.13 & 0.26 & -0.46 & 0.59 & 0.10 & 0.15 & 1116 \\
\hline No union & -0.05 & -0.05 & 0.00 & -0.05 & 0.01 & 0.00 & 0.00 & 397 \\
\hline Strike & -0.10 & -0.30 & 0.20 & -0.45 & 0.15 & -0.02 & 0.22 & 534 \\
\hline No strike & 0.40 & 0.34 & 0.07 & -0.04 & 0.38 & 0.12 & -0.05 & 970 \\
\hline
\end{tabular}

Note: figures are 1995-97 absolute changes (see section 4 for details). Legend:

WBtot $=$ non-manual share of wage bill, Etot $=$ total employment,

Wtot $=$ total wage, Ebet $=$ employment between, Ewit $=$ employment within,

Wbet $=$ wage between, $\mathrm{W}$ wit $=$ wage within. Exporter: Exp/Sales $>0.1$.

Union: presence of union members. Strike: strikes occurred. 
Table 4: Decompositions of the non-manual wage bill share by size

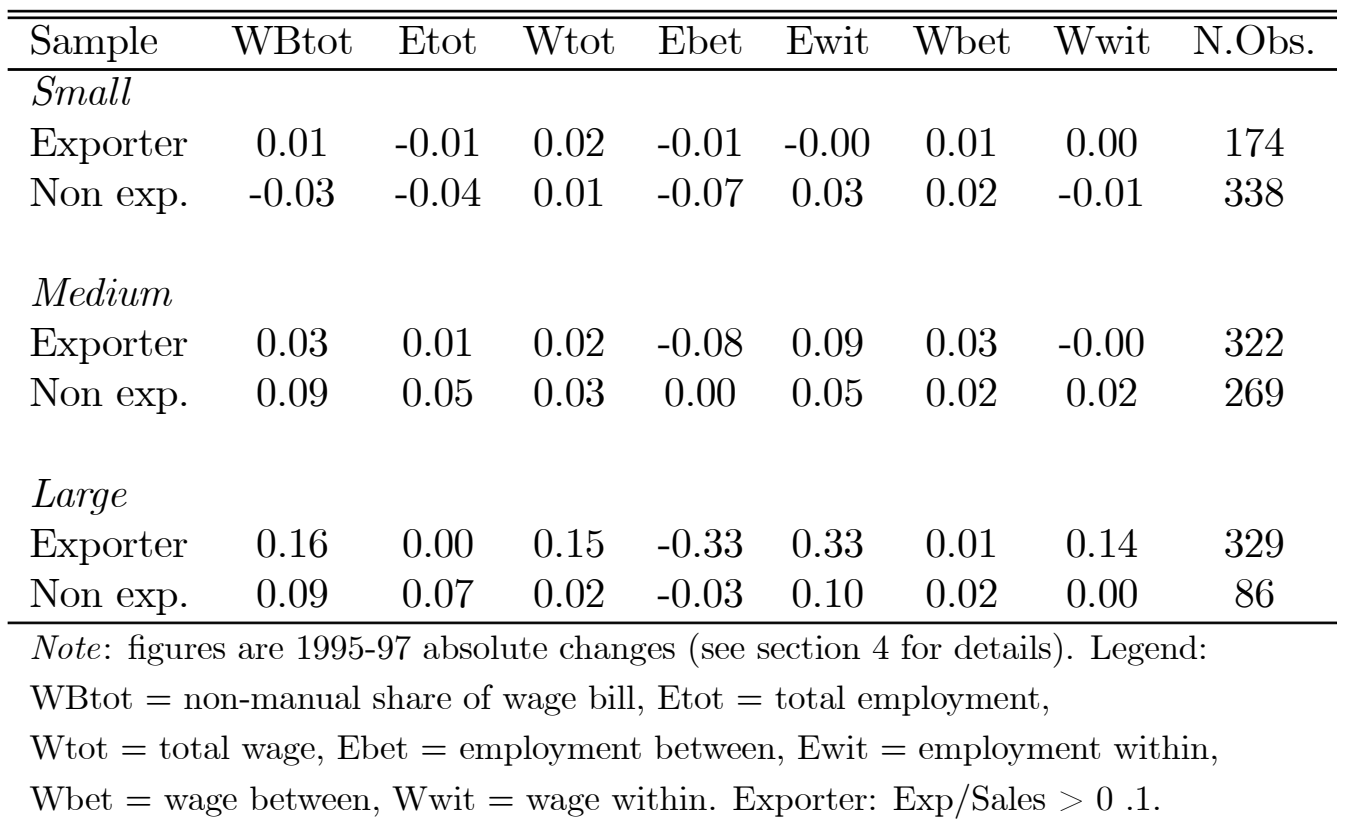

Table 5: Decompositions of the non-manual wage bill share by class

\begin{tabular}{lcccccccc}
\hline \hline Sample & WBtot & Etot & Wtot & Ebet & Ewit & Wbet & Wwit & N.Obs. \\
\hline Overall & 0.34 & 0.09 & 0.26 & -0.51 & 0.60 & 0.11 & 0.15 & 1518 \\
Executives & 0.88 & 0.70 & 0.96 & -0.41 & 1.11 & 0.06 & 0.91 & 1264 \\
Clerks & -0.53 & -0.63 & -0.71 & -0.10 & -0.52 & 0.06 & -0.77 & 1445 \\
& & & & & & & & \\
Exporter & 0.20 & 0.01 & 0.19 & -0.41 & 0.41 & 0.05 & 0.14 & 825 \\
Executives & 0.64 & 0.50 & 0.73 & -0.29 & 0.79 & 0.03 & 0.70 & 747 \\
Clerks & -0.42 & -0.48 & -0.51 & -0.12 & -0.37 & 0.04 & -0.55 & 806 \\
& & & & & & & & \\
Non export. & 0.14 & 0.08 & 0.07 & -0.10 & 0.18 & 0.05 & 0.01 & 693 \\
Executives & 0.24 & 0.20 & 0.24 & -0.12 & 0.32 & 0.03 & 0.21 & 517 \\
Clerks & -0.11 & -0.14 & -0.19 & 0.01 & -0.16 & 0.03 & -0.22 & 639 \\
\hline
\end{tabular}

Note: figures are 1995-97 absolute changes (see section 5 for details). Legend:

WBtot $=$ non-manual share of wage bill, Etot $=$ total employment,

Wtot $=$ total wage, Ebet $=$ employment between, Ewit $=$ employment within,

Wbet = wage between, Wwit = wage within. Expor ter: Exp/Sales $>0$.1. 
Table 6: Determinants of wage and employment decompositions

\begin{tabular}{lccccccc}
\hline \hline Dep. var. & Domsale & Forsale & Invamp & Invris & Invnew & Salepw & $R^{2}$ \\
\hline WBbet & 4.81 & 6.03 & 0.95 & 0.01 & 2.82 & -0.00 & 0.16 \\
& $(5.28)$ & $(6.48)$ & $(1.19)$ & $(0.01)$ & $(1.74)$ & $(-4.25)$ & \\
WBwit & -1.14 & -4.06 & -0.32 & -0.46 & 1.15 & 0.00 & 0.09 \\
& $(-2.77)$ & $(-9.62)$ & $(-0.86)$ & $(-0.80)$ & $(1.57)$ & $(3.68)$ & \\
Ebet & 5.92 & 8.37 & 1.11 & 0.13 & 1.58 & -0.00 & 0.16 \\
& $(6.74)$ & $(9.33)$ & $(1.43)$ & $(0.10)$ & $(1.01)$ & $(-4.84)$ & \\
Ewit & -1.79 & -6.02 & -0.57 & -0.21 & 2.10 & 0.00 & 0.12 \\
& $(-3.59)$ & $(-11.82)$ & $(-1.30)$ & $(-0.31)$ & $(2.36)$ & $(3.81)$ & \\
Wbet & -1.09 & -2.33 & -0.15 & -0.12 & 1.24 & 0.00 & 0.18 \\
& $(-4.81)$ & $(-10.01)$ & $(-0.76)$ & $(-0.37)$ & $(3.06)$ & $(1.63)$ & \\
Wwit & 0.64 & 1.94 & 0.25 & -0.24 & -0.94 & -0.00 & 0.30 \\
& $(3.99)$ & $(11.90)$ & $(1.80)$ & $(-1.09)$ & $(-3.32)$ & $(-2.26)$ & \\
\hline
\end{tabular}

Note: t-statistics reported in parentheses. Observations in each equation: 1315. All specifications include size, industry, and region dummies, and total 1995 employment. Legend: Domsale $=$ change in firm's domestic sales over total sales; Forsale $=$ change in firm's foreign sales over total sales; Invamp = Enlargement investment over sales; Invris $=$ Restructuring investment over sales; Invnew $=$ Investment in new products over sales; Salepw $=$ change in sales per worker. 
Table 7: Employment and wage decompositions: unweighted

\begin{tabular}{|c|c|c|c|c|c|c|c|c|}
\hline Sample & Etot & Ebet & Ewit & Wtot & Wbet & Wwit & Wcom & N.Obs. \\
\hline Overall & 0.12 & -0.38 & 0.49 & 0.60 & 0.32 & 0.48 & -0.20 & 1518 \\
\hline Small & -0.02 & -0.05 & 0.03 & -0.08 & 0.03 & 0.03 & -0.00 & 512 \\
\hline Medium & 0.12 & 0.06 & 0.06 & -0.07 & 0.14 & 0.04 & 0.01 & 591 \\
\hline Large & 0.24 & 0.07 & 0.17 & -0.36 & 0.43 & 0.03 & 0.14 & 415 \\
\hline North & 0.09 & -0.38 & 0.47 & 0.59 & 0.39 & 0.33 & -0.14 & 1261 \\
\hline Centre & 0.02 & -0.02 & 0.04 & 0.02 & -0.06 & 0.10 & -0.02 & 234 \\
\hline South & 0.00 & 0.02 & -0.02 & -0.01 & -0.01 & 0.04 & -0.04 & 23 \\
\hline Metal & -0.02 & -0.07 & 0.05 & -0.08 & 0.10 & -0.01 & -0.16 & 312 \\
\hline Machin. & 0.21 & 0.05 & 0.15 & 1.28 & 0.37 & 0.23 & 0.68 & 528 \\
\hline Precis. & -0.03 & 0.00 & -0.03 & -0.05 & -0.01 & 0.10 & -0.14 & 56 \\
\hline Electr. & -0.17 & -0.34 & 0.17 & -0.83 & -0.08 & 0.15 & -0.90 & 166 \\
\hline Transp. & 0.00 & -0.00 & 0.01 & -0.15 & -0.17 & 0.10 & -0.08 & 143 \\
\hline Other & 0.13 & -0.02 & 0.15 & 0.43 & 0.11 & -0.09 & 0.41 & 313 \\
\hline Exporter & 0.02 & -0.32 & 0.35 & 0.26 & 0.16 & 0.44 & -0.34 & 825 \\
\hline Non exp. & 0.09 & -0.05 & 0.15 & 0.33 & 0.16 & 0.04 & 0.13 & 693 \\
\hline Union & 0.14 & -0.35 & 0.49 & 0.77 & 0.33 & 0.48 & -0.04 & 1116 \\
\hline No union & -0.03 & -0.03 & 0.00 & -0.17 & -0.01 & 0.01 & -0.17 & 397 \\
\hline Strike & -0.21 & -0.35 & 0.14 & -0.63 & -0.06 & 0.68 & -1.25 & 534 \\
\hline No strike & 0.29 & -0.01 & 0.30 & 1.11 & 0.36 & -0.16 & 0.91 & 970 \\
\hline
\end{tabular}

Note: figures are 1995-97 absolute changes (see section 4 for details). Legend:

Etot $=$ total employment, Ebet $=$ empl. between, Ewit $=$ empl. with in,

Wtot $=$ total wage, Wbet $=$ wage between, $\mathrm{W}$ wit $=$ wage within, $\mathrm{Wcom}=$ wage composition. Exporter: Exp/Sales > 0.1; Union: presence of union members.

Strike: strikes occurred. 
Table 8: Employment and wage decompositions by size (unweighted)

\begin{tabular}{lcccccccc}
\hline \hline Sample & Etot & Ebet & Ewit & Wtot & Wbet & Wwit & Wcom & N.Obs. \\
\hline Small & & & & & & & & \\
Exporter & -0.01 & -0.00 & -0.00 & 0.02 & 0.05 & 0.00 & -0.03 & 174 \\
Non exp. & -0.03 & -0.06 & 0.03 & -0.11 & 0.04 & -0.01 & -0.13 & 338 \\
& & & & & & & & \\
Medium & & & & & & & & \\
Exporter & 0.01 & -0.06 & 0.07 & 0.06 & 0.07 & -0.00 & -0.01 & 322 \\
Non exp. & 0.05 & 0.01 & 0.04 & 0.24 & 0.06 & 0.04 & 0.14 & 269 \\
& & & & & & & & \\
Large & & & & & & & & \\
Exporter & 0.02 & -0.26 & 0.28 & 0.18 & 0.05 & 0.44 & -0.30 & 329 \\
Non exp. & 0.08 & -0.00 & 0.08 & 0.20 & 0.06 & 0.01 & 0.13 & 86 \\
\hline Note: figures are 1995-97 absolute changes (see section 4 for details). Legend: \\
Etot = total employment, Ebet $=$ empl. between, Ewit = empl. with in, \\
Wtot = total wage, Wbet $=$ wage between, Wwit = wage within, Wcom = wage \\
composition. Exporter: Exp/Sales $>0.1$.
\end{tabular}

Table 9: Employment and Wage decompositions by class (unweighted)

\begin{tabular}{lcccccccc}
\hline \hline Sample & Etot & Ebet & Ewit & Wtot & Wbet & Wwit & Wcom & N.Obs. \\
\hline Overall & 0.12 & -0.38 & 0.49 & 0.60 & 0.32 & 0.48 & -0.20 & 1518 \\
Executives & 0.57 & -0.29 & 0.86 & 5.04 & 0.17 & 2.84 & 2.03 & 1264 \\
Clerks & -0.46 & -0.09 & -0.37 & -4.45 & 0.19 & -2.42 & -2.22 & 1445 \\
& & & & & & & & \\
Exporter & 0.02 & -0.32 & 0.35 & 0.26 & 0.16 & 0.44 & -0.34 & 825 \\
Executives & 0.41 & -0.21 & 0.62 & 3.74 & 0.07 & 2.19 & 1.47 & 747 \\
Clerks & -0.37 & -0.11 & -0.26 & -3.35 & 0.12 & -1.74 & -1.73 & 806 \\
& & & & & & & & \\
Non export. & 0.09 & -0.05 & 0.15 & 0.33 & 0.16 & 0.04 & 0.13 & 693 \\
Executives & 0.16 & -0.08 & 0.24 & 1.30 & 0.10 & 0.65 & 0.56 & 517 \\
Clerks & -0.08 & 0.02 & -0.11 & -1.09 & 0.08 & -0.68 & -0.49 & 639 \\
\hline
\end{tabular}

Note: figures are 1995-97 absolute changes (see section 5 for details). Legend:

Etot $=$ total employment, Ebet $=$ empl. between, Ewit $=$ empl. with in,

Wtot $=$ total wage, Wbet $=$ wage between, $\mathrm{W}$ wit $=$ wage within, $\mathrm{Wcom}=$ wage composition. Exporter: Exp/Sales $>0.1$. 
Table 10: Determinants of wage and employment unweighted decompositions

\begin{tabular}{lccccccc}
\hline \hline Dep. var. & Domsale & Forsale & Invamp & Invris & Invnew & Salepw & $R^{2}$ \\
\hline Ebet & 4.55 & 6.62 & 0.92 & 0.09 & 1.25 & -2.30 & 0.16 \\
& $(6.73)$ & $(9.50)$ & $(1.53)$ & $(0.10)$ & $(1.03)$ & $(-5.09)$ & \\
Ewit & -1.16 & -4.65 & -0.46 & -0.21 & 1.55 & 0.75 & 0.12 \\
& $(-3.08)$ & $(-11.94)$ & $(-1.37)$ & $(-0.41)$ & $(2.29)$ & $(2.98)$ & \\
Wbet & -3.42 & -7.29 & -0.48 & -0.38 & 3.92 & 0.00 & 0.18 \\
& $(-4.78)$ & $(-9.97)$ & $(-0.75)$ & $(-0.38)$ & $(3.07)$ & $(1.54)$ & \\
Wwit & 1.98 & 6.09 & 0.79 & -0.75 & -2.99 & -0.00 & 0.30 \\
& $(3.94)$ & $(11.85)$ & $(1.78)$ & $(-1.08)$ & $(-3.33)$ & $(-2.18)$ & \\
\hline
\end{tabular}

Note: t-statistics reported in parentheses. Observations in each equation: 1315. All specifications include size, industry, and region dummies, and total 1995 employment. Legend: Domsale $=$ change in firm's domestic sales over total sales; Forsale $=$ change in firm's foreign sales over total sales; Invamp = Enlargement investment over sales; Invris $=$ Restructuring investment over sales; Invnew $=$ Investment in new products over sales; Salepw $=$ change in sales per worker. 